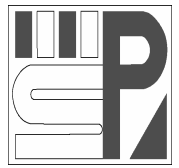

Science Press
Journal of Arid Land

2012, 4(2): 161-170

doi: 10.3724/SP.J.1227.2012.00161

jal.xjegi.com; www.chinasciencejournal.com

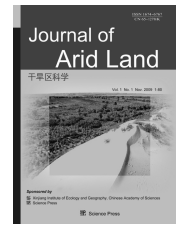

\title{
Allometric response of perennial Pennisetum cen- trasiaticum Tzvel to nutrient and water limitation in the Horqin Sand Land of China
}

\author{
Wei MAO ${ }^{1}$, TongHui ZHANG ${ }^{1 *}$, YuLin $\mathrm{LI}^{1}$, XueYong ZHAO ${ }^{1}$, YingXin HUANG ${ }^{2}$ \\ ${ }^{1}$ Naiman Desertification Research Station, Cold and Arid Regions Environmental and Engineering Research Institute, Chinese \\ Academy of Sciences, Lanzhou 730000, China; \\ ${ }^{2}$ Northeast Institute of Geography and Agroecology, Chinese Academy of Sciences, Changchun 130012, China
}

\begin{abstract}
Optimal partitioning theory (OPT) suggests that plants should allocate relatively more biomass to the organs that acquire the most limited resources. The assumption of this theory is that plants trade off the biomass allocation between leaves, stems and roots. However, variations in biomass allocation among plant parts can also occur as a plant grows in size. As an alternative approach, allometric biomass partitioning theory (APT) asserts that plants should trade off their biomass between roots, stems and leaves. This approach can minimize bias when comparing biomass allocation patterns by accounting for plant size in the analysis. We analyzed the biomass allocation strategy of perennial Pennisetum centrasiaticum Tzvel in the Horqin Sand Land of northern China by treating samples with different availabilities of soil nutrients and water, adding snow in winter and water in summer. We hypothesized that $P$. centrasiaticum alters its pattern of biomass allocation strategy in response to different levels of soil water content and soil nitrogen content. We used standardized major axis (SMA) to analyze the allometric relationship (slope) and intercept between biomass traits (root, stem, leaf and total biomass) of nitrogen/water treatments. Taking plant size into consideration, no allometric relationships between different organs were significantly affected by differing soil water and soil nitrogen levels, while the biomass allocation strategy of $P$. centrasiaticum was affected by soil water levels, but not by soil nitrogen levels. The plasticity of roots, leaves and root/shoot ratios was 'true' in response to fluctuations in soil water content, but the plasticity of stems was consistent for trade-offs between the effects of water and plant size. Plants allocated relatively more biomass to roots and less to leaves when snow was added in winter. A similar trend was observed when water was added in summer. The plasticity of roots, stems and leaves was a function of plant size, and remained unchanged in response to different soil nitrogen levels.
\end{abstract}

Keywords: optimal partitioning; allometric biomass partitioning; limited resources; biomass allocation; allometric relationships

Biomass allocation in plants is a key ecological issue (McConnaughay and Coleman, 1999). Understanding biomass allocation strategies across environments can help explain plant distribution and abundance. There are some debates about the mechanisms that control these processes (McCarthy and Enquist, 2007; Kobe et al., 2010). Optimal partitioning theory (OPT) predicts that a plant should allocate relatively more biomass to the organs that acquire the most limited resources (Bloom et al., 1985). For instance, under low light conditions, OPT predicts that a plant will allocate proportionally more biomass to leaves (Shipley and Meziane, 2002), while under low soil nitrogen conditions more biomass will be allocated to the roots (Linkohr et al., 2002; Mony et al., 2007).

However, the generality of OPT has been questioned (Coleman and McConnaughty, 1995; McCarthy and Enquist, 2007). OPT regards plant allocation as being size-dependent, and in fact almost all such patterns are size-dependent (Pino et al., 2002). Moreover,

Received 2011-10-24; accepted 2012-01-31

*Corresponding author: TongHui ZHANG (E-mail: zhangth@1zb.ac.cn) 
the variations in biomass allocation among plant parts are not only caused by environmental conditions but also by plant size (Müller et al., 2000; Bonser and Aarssen, 2009). For example, although many studies have supported predications made by OPT, plants have been shown to allocate more biomass to roots when water and nutrients are limited (Linkohr et al., 2002; Mony et al., 2007), and recent studies suggested that the changes in plant size may lead to the variation in biomass allocation when root/shoot ratios are used (McCarthy and Enquist, 2007). The root/shoot ratio is expected to change with plant size if organ masses do not scale isometrically to each other. Therefore, if OPT is applied, it is difficult to distinguish between variations in biomass allocation patterns due to resource limitations in the environment ('true' plasticity) versus size-dependent allometrically-driven patterns ('apparent' plasticity) (Zhang and Jiang, 2002; Weiner, 2004; McCarthy and Enquist, 2007). Although apparent plasticity has been demonstrated in many species, the distinguishing between apparent and true plasticity requires a cautious allometric analysis.

As an alternative approach, allometric biomass partitioning theory (APT) is useful for resolving increasingly contentious debates concerning biomass allocation (Solow, 2005), because it minimizes bias when comparing biomass allocation patterns by accounting for plant size in the analysis (McCarthy and Enquist, 2007). According to APT, the variability due simply to the size of a plant is removed prior to analysis via use of standardized major axis (SMA) regression (McConnaughay and Coleman, 1999; Yang and Luo, 2011). Under this hypothesis, the allometric relationships that exist among different organs of plants are consistent regardless of variation in the environment. The examples include the above- and belowground biomasses in four white pine species (Peichl and Arain, 2007).

The perennial grass Pennisetum centrasiaticum Tzvel is a key species in Horqin Sand Land of northern China. In the restoration processes of vegetation, the plant species is a driver of changes in community environment and makes a great contribution to the maintenance of community function (Zhang et al., 2005). It allocates relatively more biomass to roots in low water conditions (Guo and $\mathrm{Li}, 2008$ ) and grows well in variational environments in different sandy lands. This suggests that the biomass allocation strategy of $P$. centrasiaticum supports OPT. However, previous studies have not considered the effect of plant size on biomass allocation pattern (Liu et al., 1999; Chen et al., 2002). If plant size is accounted for, then it is not clear if $P$. centrasiaticum's biomass allocation strategy still supports OPT or not.

In the Horqin Sand Land, the desertification caused by land use and climate change has resulted in the conversion of $71,884 \mathrm{~km}^{2}$ of former arid and semi-arid grasslands into shrublands and open sandy dunes (Zhao et al., 2004). This land degradation has significantly altered the nitrogen and water contents of the soil (Li et al., 2005). Nitrogen and water are the two important limited factors for plants in arid regions ( $\mathrm{Li}$ et al., 2005; Huang et al., 2009a, b). Along these sand dune habitats, plants are likely to exhibit varied biomass allocation patterns in response to different resource limitations (e.g. low to medium water and soil nutrient content). Plants surviving in shifting sand dunes would allocate more biomass to roots, rather than to leaves, in response to nutrient limitations (Huang et al., 2009a).

Snow is a potential source of water and it is important for ecophysyiological process like root respiration and biomass allocation of plants (Wipf, 2010). For instance, increasing the snow cover can affect biomass allocation pattern in the weed Achillea millefolium in the Australian Alps (Johnston and Johnston, 2004). However, such studies of responses of plant biomass allocation patterns to changes in snow in the Horqin Sand Land are rare. We performed a controlled manipulative experiment in the field with perennial $P$. centrasiaticum under different treatments of nitrogen and water (snow added in winter and water added in summer) to answer the following three questions: (1) do the biomass allocation patterns of $P$. centrasiaticum vary in response to changes in environmental conditions, especially to snow? (2) If yes, do the biomass allocation strategies of this species represent 'apparent' or 'true' plasticity? and (3) after taking the effect of plant size into consideration, do the biomass allocation strategies of the species still support OPT? We hypothesized that (1) the biomass allocation pattern of $P$. centrasiaticum would be altered in response to changes in availability of limited resources; and (2) the allocation strategy of $P$. centrasiaticum would not 
support the OPT, but support APT because the allometric relationships among different organs would be constant at different levels of nitrogen and water.

\section{Materials and methods}

\subsection{Study area}

The experiment was conducted in the central part of the Horqin Sand Land in eastern Inner Mongolia, China $\left(42^{\circ} 55^{\prime} \mathrm{N}, 120^{\circ} 42^{\prime} \mathrm{E}, 345 \mathrm{~m}\right.$ asl). The soils are very infertile and sandy with a light yellow color, coarse texture and loose structure. The soil total nitrogen content is around 0.057-0.199 and the soil bulk density is $1.29-1.59 \mathrm{~g} / \mathrm{cm}^{3}$ in the $0-30 \mathrm{~cm}$ depth (Zhao et al., 2007). The local climate belongs to temperate, continental and semiarid monsoon, with a mean annual temperature of $6.8^{\circ} \mathrm{C}$ and an annual precipitation of $366 \mathrm{~mm}$ (Fig. 1), and a mean annual potential evaporation of $1,935 \mathrm{~mm}$. The annual frost-free period is approximately 130 to 150 days.

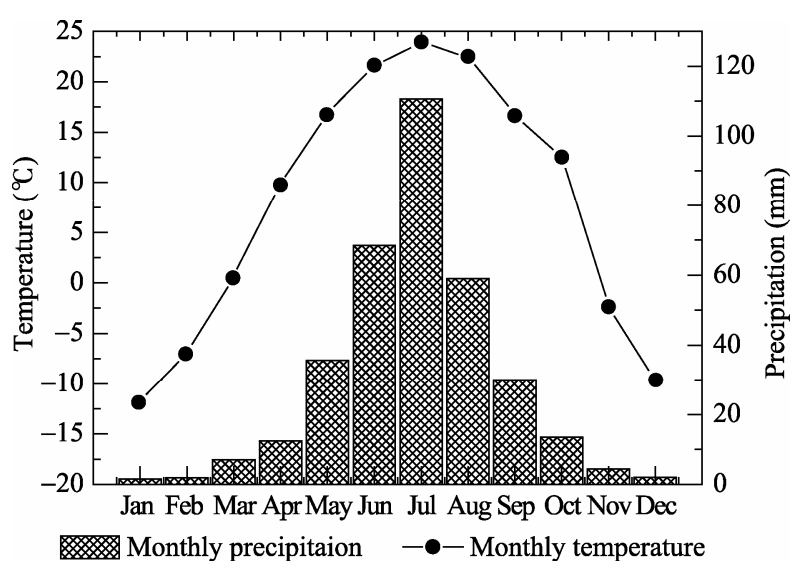

Fig. 1 Multi-year (1988-2008) average of monthly temperature and precipitation in Horqin Sand Land of Inner Mongolia

The dunes of the sandy area are alternately distributed within a gently undulating lowland (Li et al., 2005). The vegetation is characterized by shrublands of Artemisia halodendron Lam with scattered trees and shelterbelts of Populus spp. Plant canopy covers are between $15 \%$ and $60 \%$, which presents a random patchy structure. The dominant plant species include $P$. centrasiaticum, A. halodendron, Caragana microphylla Turcz ex Bess and Setaria viridis (L.) Beauv.

\subsection{Materials}

Pennisetum centrasiaticum Tzvel in this study area is a dominant species in the slightly degraded sandy grassland. The perennial herb $P$. centrasiaticum is a $\mathrm{C}_{4}$ clonal plant, culms solitary or clump, its growth season being from April to October, and it is a key species in the early successional stages of the desertificated grasslands in northern China (Liu et al., 1999) due to its possession of higher root/shoot ratio (RSR) values than many other species. $P$. centrasiaticum has been shown to exhibit some apparent plasticity (Liu et al., 1999; Guo and Li, 2008). The relative biomass of roots (RR) of $P$. centrasiaticum increases in arid and semiarid environments compared to moist environments (Chen et al., 2002).

\subsection{Experimental design}

On 5 October, 2009, 36 plastic pots $(30 \mathrm{~cm}$ in diameter and $40 \mathrm{~cm}$ in height) were planted in a community dominated by $P$. centrasiaticum. Two treatments (N addition and water addition) were chosen to reflect both stressed and unstressed habitats in May 2010. N addition includes two treatments: one is $\mathrm{N}$ unstressed $\left(\mathrm{N}_{+}\right)$, under which $2.02 \mathrm{~g}$ of $\mathrm{NH}_{4} \mathrm{NO}_{3}$ was added on 8 June; and another is control $\left(\mathrm{N}_{\mathrm{o}}\right.$; stressed and the total nitrogen content is $34 \mathrm{mg} / \mathrm{kg}$ in the $0-40 \mathrm{~cm}$ soil depth). The soil nitrogen content in $\mathrm{N}_{+}$treatment is equal to the soil nitrogen level in the restored sandy land (Su et al., 2004).

Water treatments include water addition in summer, snow addition in winter and a control. $\mathrm{W}_{\mathrm{w}^{+}}$denotes high snow level (snow added in winter). There was heavy snow on 12 November, 25 December and 14 March. We collected the snow, of which 1,000 g was added in each pot, approximately $30 \%$ of local average precipitation during the growth season in the recent 20 years (Fig. 1).

$\mathrm{W}_{\mathrm{s}^{+}}$denotes high water level (water added in summer; from June to August, 2010), being equal to 100 $\mathrm{mm}$ rainfall during the growing season. Water $(1,000$ $\mathrm{ml}$ ) was applied to each pot every 2 weeks (approximately $30 \%$ of the average precipitation during the growth season). $\mathrm{W}_{\mathrm{o}}$ denotes low water/snow level, under which no additional water was added. A full-factorial design of six possible combinations of high/low levels of nitrogen and high/low levels of water/snow was constructed. There were six pots in every treatment and 36 pots in total. In each pot, there were three to eight $P$. centrasiaticum plants. Relative values in the analysis were used to minimize the effect of density. In addition, Huang et al. (2009a, b) found that 
plant density would not affect the biomass allocation strategy of many desert plants. As the population of $P$. centrasiaticum counts on self thinning under undisturbed conditions, the effect of it is weak compared to the effect caused by nitrogen and water treatments. Therefore, we did not consider the effect of density on biomass allocation strategy of $P$. centrasiaticum in the study.

\subsection{Measurements}

Plants were harvested collectively in mid-September of 2010. We took out the plants and soil from the pots carefully, and then washed the roots with tap water to remove the soil. After that, we sank all the plants into water and swung gently to separate the roots of each species from each other. Six pots of plants from each treatment were randomly selected for the measurement of biomass traits. All individuals were numbered, and each individual was separated by leaves, stems, roots and reproductive organs. The dry masses for all parts were determined after oven-drying them to a constant weight at $80^{\circ} \mathrm{C}$. Most individuals of $P$. centrasiaticum had not produced sufficient reproductive organs for analysis at that time, so we included all available reproductive biomasses in total biomass. The following traits were recorded for each individual plant: root biomass (BRO), stem biomass (BS), leaf biomass (BL), reproductive biomass (BRE) and total biomass (BT). We used those measurements to calculate: Root/shoot ratio $(\mathrm{RSR})=\mathrm{BRO} /(\mathrm{BS}+\mathrm{BL}+\mathrm{BRE})$; Relative biomass of stems $(\mathrm{RS})=\mathrm{BS} / \mathrm{BT}$; Relative biomass of leaves $(\mathrm{RL})=\mathrm{BL} / \mathrm{BT}$; Relative biomass $(\mathrm{RR})=\mathrm{BRO} / \mathrm{BT}$.

\subsection{Data analysis}

A two-way analysis of variance (ANOVA) was performed to test the effects of nitrogen and water on biomass allocation traits of $P$. centrasiaticum. Data were analyzed with SPSS statistical software (version 17.0; SPSS Inc., Chicago, IL, USA).

We tested for changes in allometric relationship between traits within each treatment via SMA regressions (one kind of Model II regression) and by fitting trait values to the following allometric equation: $y=\gamma$ $x^{\beta}$. All variables (biomass traits) were log transformed, so that the above equation can be re-expressed as: $Y=\log (\gamma)+\beta X ; Y=\alpha+\beta X$, where we have made the substitutions $Y=\log (y), X=\log (x)$, and $\alpha=\log (\gamma) . \beta$ is the scaling exponent (slope) and $\alpha$ is the allometric coef- ficient of 'scaling factor' ( $Y$ intercept). If the $\beta$ changes, the allometric relationship also changes, which indicates that at a given $X$ the $Y$ value will change (Warton et al., 2006). If the $\alpha$ increases, it indicates that at a given $X$ there will be a higher $Y$ value, or at a given $Y$ there will be a higher $X$ value. For instance, $X$ indicates total biomass and $Y$ indicates root biomass. If $\alpha$ increases, the biological significance is that at a given total biomass plants invest more biomass to roots, which suggests higher $\alpha$ gains from additional mass investment in roots. On log-log axes, SMA (standardized major axis) (Esmaeili et al., 2009) describes the best-fit scaling relationships between pairs of traits. Slopes on log-log axes, or 'scaling exponents', indicate the proportionality of pairwise trait relationships (Wright et al., 2004). Heterogeneity between SMA slopes is tested via a permutation (Warton et al., 2006) and the test for differences in SMA intercept via the SMA analogue of standard ANCOVA (Wright et al., 2002). Intercept homogeneity comparisons were performed only when the slopes were homogeneous. The slopes and intercepts of every water and nitrogen treatment were then calculated using the 'smatr' package for R (R Development Core Team, 2009).

\section{Results}

\subsection{Plasticity of biomass traits and allocation}

Water treatments (both for snow added in winter and water added in summer) significantly altered biomass allocation in $P$. centrasiaticum. On average, total biomass per species in $\mathrm{W}_{\mathrm{s}^{+}}$was 1.81 times as much as that in $\mathrm{W}_{\mathrm{w}^{+}}$treatments. RSR values decreased when soil water level increased. The RSR value in $\mathrm{W}_{\mathrm{w}^{+}}$was similar with that in the $\mathrm{W}_{\mathrm{s}^{+}}$treatment and was about 0.53 times lower compared to the RSR value in $\mathrm{W}_{\mathrm{o}}$ treatments $(P<0.05)$. The $\mathrm{RL}$ and the $\mathrm{RS}$ in $\mathrm{W}_{\mathrm{w}^{+}}$ treatment were higher and RR was lower than those in low snow level ( $\mathrm{W}_{\mathrm{o}}$ treatments). The $\mathrm{RL}$ and the $\mathrm{RS}$ in $\mathrm{W}_{\mathrm{s}^{+}}$treatment were also higher than those in $\mathrm{W}_{\mathrm{o}}$ treatments, while RR was lower in $\mathrm{W}_{\mathrm{s}^{+}}$treatment $(P<0.01)$.

However, the nitrogen level did not affect the biomass traits of $P$. centrasiaticum (Table 1). The interaction of water level and nitrogen level had a significant effect on RR, RL and RSR $(P<0.01)$. The biomass 
Table 1 Results of a two-way ANOVA testing the effects on biomass allocation traits of $P$. centrasiaticum

\begin{tabular}{ccccccc}
\hline Factor & $d f$ & Total & RSR & RR & RS & RL \\
\hline Nitrogen $(\mathrm{N})$ & 1 & 0.375 & 1.264 & 1.857 & 0.016 & 3.17 \\
Water $(\mathrm{W})$ & 2 & $8.89^{* * *}$ & $9.26^{* * *}$ & $8.85^{* * *}$ & $4.64^{* *}$ & $8.39^{* * *}$ \\
$\mathrm{~N} \times \mathrm{W}$ & 2 & 2.18 & $4.74^{*}$ & $4.00^{*}$ & 2.96 & $4.32^{*}$
\end{tabular}

Note: RSR, Root/shoot ratio; RR, Relative biomass of roots; RS, Relative biomass of stems; RL, Relative biomass of leaves. Data were log transformed before analysis. The residual $d f$ is 56 for each parameter. $F$-values are presented. ", "** and ${ }^{* * *}$ indicate significance at $P<0.05, P<0.01$ and $P<0.001$, respectively.

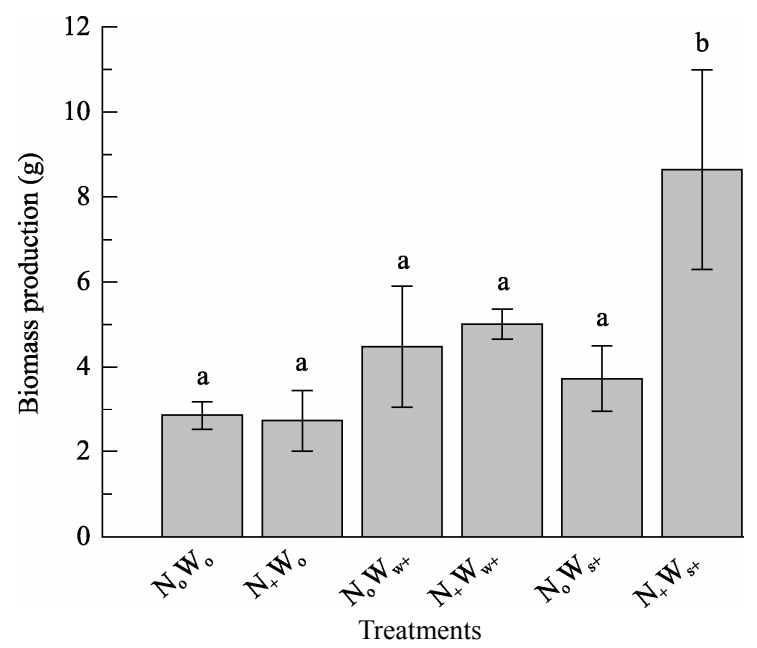

Fig. 2 Effect of nitrogen $(\mathrm{N})$ and water $(\mathrm{W})$ on relative biomass of roots, relative biomass of stems, relative biomass of leaves and root/shoot ratios in $P$. centrasiaticum. Different letters indicate significant difference among treatments $(P<0.05)$. Data are means $\pm S E$ and are averaged across treatments.

production was significantly higher in $\mathrm{N}_{+} \mathrm{W}_{\mathrm{s}^{+}}$treatment (Fig. 2).

\subsection{Allometric relationships among biomass allo- cation traits}

All relationships for pairwise comparisons of biomass allocations were significantly positive (Table 2, Fig. 3). For $P$. centrasiaticum, the allometic relationship (slope, $\beta$ ) of bivariate biomass traits was not affected by water, while the intercepts (allometric coefficient, $\alpha$ ) between root biomass and shoot biomass, leaf biomass and total biomass, and root biomass and total biomass were affected by soil water content. The intercept between root biomass and shoot biomass was higher $(P<0.05)$ while the intercept between root biomass and total biomass was lower $(P<0.01)$ in $\mathrm{W}_{\mathrm{o}}$ treatment compared to those in $\mathrm{W}_{\mathrm{w}^{+}}$treatment and $\mathrm{W}_{\mathrm{s}^{+}}$treatment.

The allometric relationship and allometric coeffi- cient were not influenced by soil nitrogen availability (Table 2).

\section{Discussion}

P. centrasiaticum altered biomass allocation strategies in response to soil water content, but not in response to soil nitrogen content. This indicated that the plasticity of the biomass traits for water treatments was higher than that for nitrogen treatments. These partly support our first hypothesis, and the biomass allocation pattern of $P$. centrasiaticum was altered in response to different soil water levels. The result is consistent with previous studies (Ren et al., 2000), which suggested that the biomass allocation pattern of $P$. centrasiaticum in abandoned farmland was closely related to soil water content, and not to soil nutrient content. Further, we found that none of the allometric relationships (slope) between biomass traits changed with different soil water and soil nitrogen levels. This result supports the second hypothesis, and the result from perennial $P$. centrasiaticum supports the theory of allometric biomass partitioning.

\subsection{Allometric relationships between root and shoot biomass}

Our RSR values were significantly affected by water levels, which is consistent with former studies (Mony et al., 2007; Huang et al., 2009a). Higher ratios were resulted from deficiencies in soil water content (Mony et al., 2007). RSR in $\mathrm{W}_{\mathrm{w}+}$ treatment have similar values with RSR in $\mathrm{W}_{\mathrm{s}+}$, and these values were lower than those in $\mathrm{W}_{\mathrm{o}}$ treatment. The intercepts of root biomass and shoot biomass were lower in $\mathrm{W}_{\mathrm{w}^{+}}$treatment. This suggests that at a given root biomass, the proportion of $P$. centrasiaticum shoot biomass in $\mathrm{W}_{\mathrm{w}^{+}}$ treatment is higher than that in $\mathrm{W}_{\mathrm{o}}$ treatment, which indicates that the plasticity of RSR is 'true' in response to water.

Neither RSR values nor the allometric relationships between root and shoot biomasses in P. centasiaticum were significantly affected by soil nitrogen level, which suggests no plasticity of RSR occurred in response to nitrogen. The allometric relationships between roots and shoots were not significantly affected by nitrogen levels. This contrasts with the conclusions put forward by Shipley on twenty-two herbaceous species(Shipley and Meziane, 2002), in which nutrient su- 
Table 2 Allometric relationships between relative organbiomass of $P$. centrasiaticum

\begin{tabular}{|c|c|c|c|c|c|c|c|}
\hline Group & Treatment & $\mathrm{n}$ & $r^{2}$ & Slope & Intercept & $\begin{array}{c}P \text { value for } \\
\text { slope }\end{array}$ & $\begin{array}{c}P \text { value for } \\
\text { intercept }\end{array}$ \\
\hline \multirow[t]{2}{*}{ A } & $\mathrm{N}_{\mathrm{o}}$ & 18 & 0.98 & 0.72 & 1.02 & 0.60 & 0.79 \\
\hline & $\mathrm{N}_{+}$ & 18 & 0.99 & 0.64 & 1.00 & & \\
\hline \multirow[t]{2}{*}{ B } & $\mathrm{N}_{\mathrm{o}}$ & 18 & 0.50 & 1.55 & -2.14 & 0.94 & 0.47 \\
\hline & $\mathrm{N}_{+}$ & 18 & 0.90 & 1.52 & -2.19 & & \\
\hline \multirow[t]{2}{*}{$\mathrm{C}$} & $\mathrm{N}_{\mathrm{o}}$ & 18 & 0.73 & 1.34 & -1.71 & 0.43 & 0.46 \\
\hline & $\mathrm{N}_{+}$ & 18 & 0.99 & 1.54 & -1.67 & & \\
\hline \multirow[t]{2}{*}{ D } & $\mathrm{N}_{\mathrm{o}}$ & 18 & 0.95 & 0.98 & -0.02 & 0.84 & 0.35 \\
\hline & $\mathrm{N}_{+}$ & 18 & 0.94 & 0.97 & -0.03 & & \\
\hline \multirow[t]{3}{*}{ A } & $\mathrm{W}_{\mathrm{o}}$ & 12 & 0.64 & 0.65 & $1.08^{\mathrm{b}}$ & 0.20 & * \\
\hline & $\mathrm{W}_{\mathrm{s}^{+}}$ & 12 & 0.93 & 0.82 & $0.99^{\mathrm{a}}$ & & \\
\hline & $\mathrm{W}_{\mathrm{w}+}$ & 12 & 0.70 & 0.56 & $0.94^{\mathrm{a}}$ & & \\
\hline \multirow[t]{3}{*}{ B } & $\mathrm{W}_{\mathrm{o}}$ & 12 & 0.54 & 1.57 & -2.16 & 0.10 & 0.10 \\
\hline & $\mathrm{W}_{\mathrm{s}^{+}}$ & 12 & 0.94 & 1.15 & -2.07 & & \\
\hline & $\mathrm{W}_{\mathrm{w}^{+}}$ & 12 & 0.69 & 1.94 & -2.00 & & \\
\hline \multirow[t]{3}{*}{$\mathrm{C}$} & $\mathrm{W}_{\mathrm{o}}$ & 12 & 0.70 & 1.56 & $-1.76^{\mathrm{b}}$ & 0.35 & * \\
\hline & $\mathrm{W}_{\mathrm{s}+}$ & 12 & 0.95 & 1.25 & $-1.65^{\mathrm{a}}$ & & \\
\hline & $\mathrm{W}_{\mathrm{w}^{+}}$ & 12 & 0.82 & 1.60 & $-1.59^{\mathrm{a}}$ & & \\
\hline \multirow[t]{3}{*}{ D } & $\mathrm{W}_{\mathrm{o}}$ & 12 & 0.69 & 1.00 & $-0.016^{\mathrm{a}}$ & 0.29 & $* *$ \\
\hline & $\mathrm{W}_{\mathrm{s}^{+}}$ & 12 & 0.78 & 0.98 & $-0.034^{b}$ & & \\
\hline & $\mathrm{W}_{\mathrm{w}^{+}}$ & 12 & 0.76 & 0.92 & $-0.042^{\mathrm{c}}$ & & \\
\hline
\end{tabular}

Note: A, root biomass $(X)$ and shoot biomass $(Y)$ for different treatments; B, stem biomass $(X)$ and total biomass $(Y)$ for different treatments; C, leaf biomass $(X)$ and total biomass $(Y)$ for different treatments; D, root biomass $(X)$ and total biomass $(Y)$ for different treatments. Dates were log transformed before analysis. Different letters indicate significant difference among treatments at $P<0.05$. "and " indicate significance at $P<0.05$ and $P<0.01$, respectively.
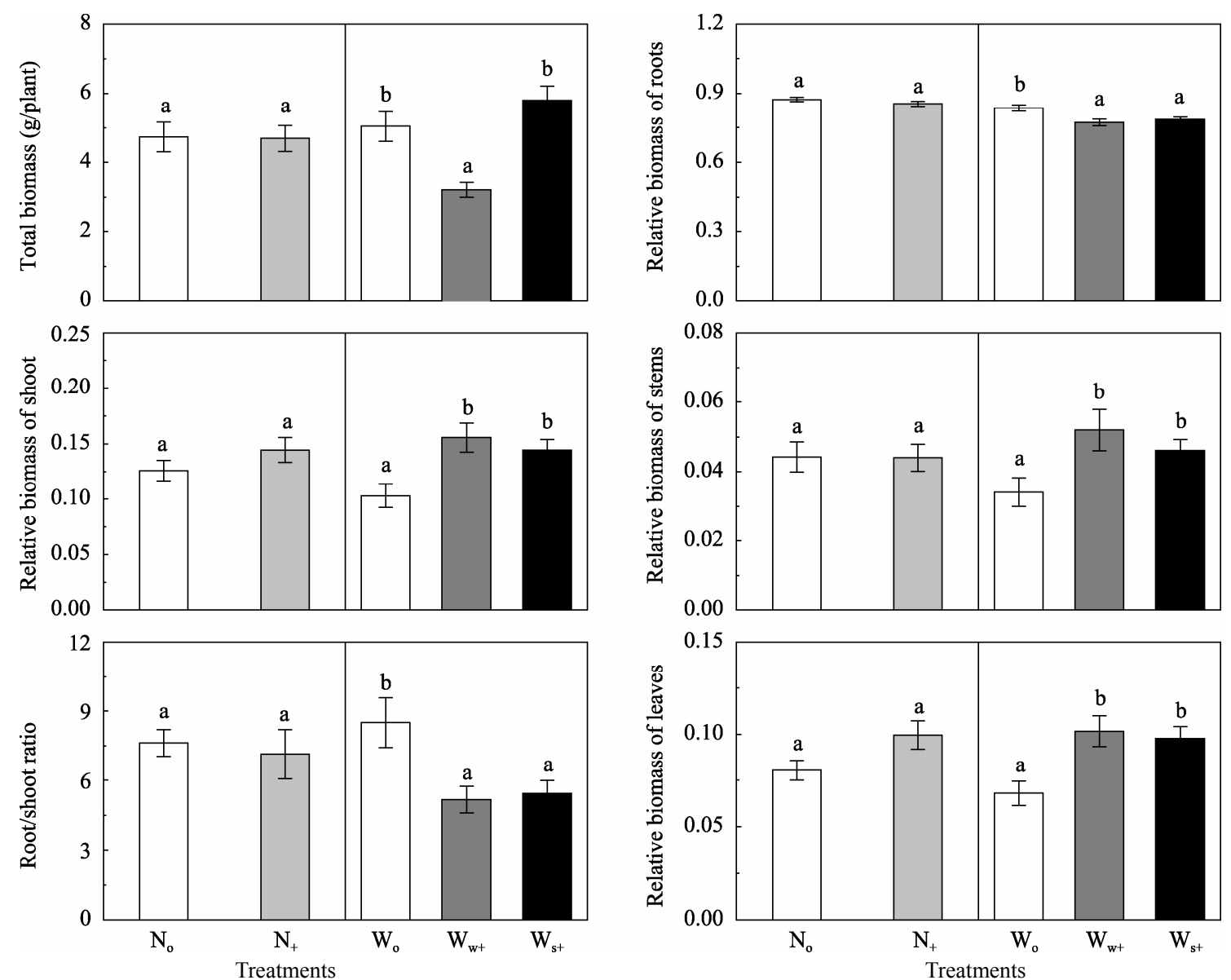

Fig. 3 Effect of nitrogen $(\mathrm{N})$ and water $(\mathrm{W})$ on biomass production of $P$. centrasiaticum. Different letters indicate significant difference among treatments $(P<0.05)$. Data are means \pm SE and were averaged across treatments. 

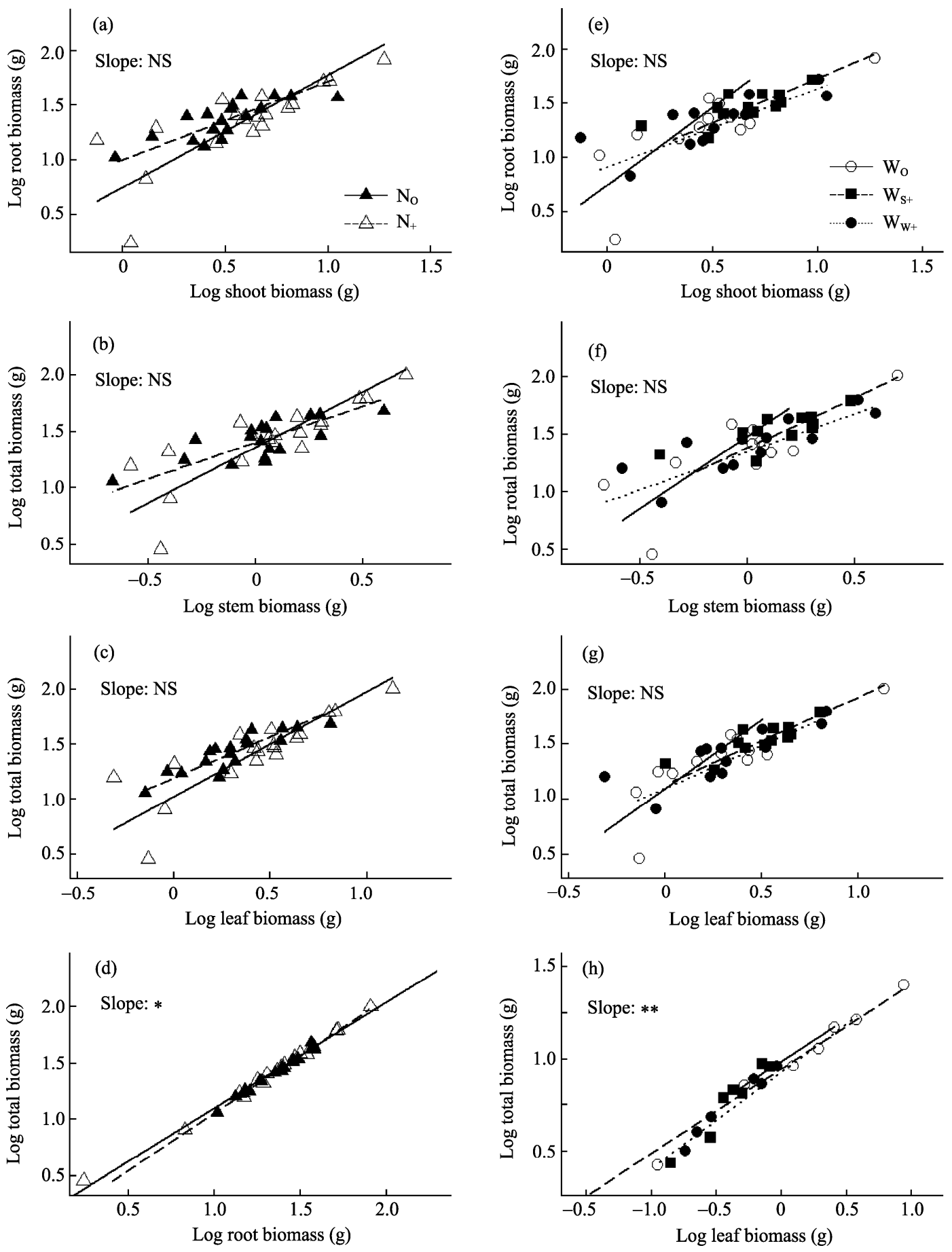

Fig. 4 Allometic relationship of different organs of $P$. centrasiaticum. a-d, allometric relationships of each nitrogen supply level; e-h, allometric relationship of each water supply level. * and ** indicate significance at $P<0.05$ and $P<0.01$, respectively; NS means no significance at $P<0.05$.

pply affected the slope and the intercept between fact that the effect of plant size on allocation to roots and to shoots was consistent.

\subsection{Allometric relationships between root and total biomass}

The allometric relationships between root and total biomass were not affected by soil water levels, but the intercept of root and total biomass did change with increasing water, which means at a given total biomass, the proportion of biomass invested into roots increases. Therefore, the relative biomass of roots of $P$. centrasiaticum was 'true' in response to water. This is in 
agreement with the study by Ren et al. (2000), which suggested the root biomass of $P$. centrasiaticum increased with the increase of soil water content, and soil water also increased the number of adventitious buds per unit length of rhizome.

The RR values, allometric relationship, and intercept of root biomass and total biomass of $P$. centrasiaticum were not affected by soil nitrogen level, and therefore, the plasticity on RR of $P$. centrasiaticum was 'nonexistent' in response to water. These results are in contrast with previous studies: lack of nitrogen results in accumulation of carbohydrate in leaves, higher levels of carbon invested to the root, and biomass allocation in the direction of a shift from leaves to roots (Linkohr et al., 2002; Hermans et al., 2006). Therefore, at low nitrogen levels, plants often have a larger proportion of root biomass. However, at high nitrogen levels, $P$. centrasiaticum developed more ramets to occupy resources (Ren et al., 2000; Chen et al., 2002) instead of increasing the root biomass of per ramet. $P$. centrasiaticum is a kind of rhizome grass, expanding its population with small and numerous ramets, and has highly developed rhizomes in the $0-20 \mathrm{~cm}$ layer of the soil (Guo and Li, 2008). This strategy of $P$. centasiaticum leads to more tolerance with variation in soil nitrogen content and this characteristic may be what enables the perennial grass to be dominant over other species in nutrient-poor habitats.

The variation in root/shoot ratio indicated a coordinated growth of roots and shoots in order to trade off the water demand of the transpiring leaf surface with the water uptake capacity of the root system (Gao et $a l .$, 2011). At low soil water levels, water uptake per unit root mass will be decreased, and nutrient uptake will also be reduced, which would make the delivery of nutrients by mass flow be hampered in dry soil (Poorter and Nagel, 2000). These factors are expected to increase ratios of root biomass. Whereas, biomass of aboveground parts (leaves and stems) decreased in order to reduce the whole plant transpiration (Gao et al., 2011), leading to higher RSR values.

\subsection{Allometric relationships between stem and total biomass}

The RS value of stems was significantly affected by water (Table 1), while the slope and intercept of leaf biomass and total biomass were identical under different levels of moisture availability, leading to an 'apparent' plasticity. This suggested that the variations in RS were not caused by soil water content.

In contrast to former studies (Müller et al., 2000; Wang et al., 2008), which suggested that plants allocate more biomass to stems when grown in high soil nutrient levels, our RS was unaffected by soil nitrogen level. Neither allometric relationship nor intercept between stem and total biomass was affected by nitrogen. This suggested that no plasticity occurred for stem biomass allocation with regard to nitrogen (Table 3). These results disagreed with previous studies (Müller et al., 2000), which indicated that plants in lower nutrient levels tended to allocate relative more biomass to stems irrespective of plant size. The reason is that although available nitrogen was increased at high nitrogen levels, $P$. centrasiaticum may develop more ramets to use the resource (Chen et al., 2002) instead of shifting biomass allocation to stems.

Table 3 Plasticity of biomass allocations of $P$. centrasiaticum for different treatments

\begin{tabular}{ccc}
\hline Parameter & Treatment & Plasticity \\
\hline RSR & Nitrogen & Nonexistent \\
& Water & True \\
RR & Nitrogen & Nonexistent \\
& Water & True \\
RL & Nitrogen & Nonexistent \\
& Water & True \\
RS & Nitrogen & Nonexistent \\
& Water & Apparent \\
\hline
\end{tabular}

Note: Plasticity is 'apparent' if relationships are not significantly affected by environmental conditions at $P>0.05$; 'true' if allometric relationships (or intercept) are significantly affected by environmental conditions at $P<0.05$; and 'nonexistent' if biomass traits and allometric relationships (or intercept) are both not significantly affected by environmental conditions at $P>0.05$.

\subsection{Allometric relationships between leaf and total biomass}

This experiment clearly demonstrated that the intercept between leaf and total biomass was significantly affected by water treatments (both for snow added in winter and water added in summer). The intercept between leaf and total biomass decreased when soil water increased. These suggested that at a given total biomass, the proportion of biomass invested into roots increased and the amount invested into leaves decreased. Therefore, the plasticity of leaves of $P$. centrasiaticum was 'true' in response to water (both for snow added in winter and water added in summer), which suggested that snow added in winter and water 
added in summer had altered the pattern of leaf biomass allocation.

When soil nutrient content was deficient, plants invested more biomass to their organs than to their leaves (Wang et al., 2008). Here, allometric relationship (slope) and intercept between leaf and total biomass were not influenced by nitrogen (Table 2), so that no plasticity occurred for leaf allocation with regard to soil nitrogen content.

\section{Conclusions}

Significant relationships were found between different biomass traits of $P$. centrasiaticum, and biomass allocation strategies showed different patterns in response to nitrogen and water levels. In response to nitrogen content, the plasticity of root, stem and leaf biomass allocation was 'nonexistent' at high nitrogen levels compared to low nitrogen levels because of the trade-off between the effect of plant size and nitrogen level. In response to water content, plasticity was 'true' for RR, RSR and RL. At a low water level, $P$. centrasiaticum allocated more biomass to roots than to aboveground parts. Snow added in winter did not increase the total biomass, but changed the root/shoot

\section{References}

Bloom A J, Chapin F S, Mooney H A. 1985. Resource limitation in plants - an economic analogy. Annual Review of Ecology and Systematics, 16(1): 363-392.

Bonser S P, Aarssen L W. 2009. Interpreting reproductive allometry: individual strategies of allocation explain size-dependent reproduction in plant populations. Perspectives in Plant Ecology. Evolution and Systematics, 11(1): 31-40.

Chen S P, Gao Y B, Ren A Z, et al. 2002. Ecological adaptability of Pennisetum centrasiaticum clones on farmlands and dune ecotone of Keerqin Sandy Land. Chinese Journal of Ecology, 13(1): 45-49.

Coleman J S, McConnaughty K D M. 1995. A non-functional interpretation of a classical optimal-partitoning example. Functional Ecology, 9(6): 951-954.

Esmaeili M M, Bonis A, Bouzillé J B, et al. 2009. Consequence of ramet defoliation on plant clonal propagation and biomass allocation: example of five rhizomatous grassland species. Flora-Morphology, Distribution, Functional Ecology of Plants, 204(1): 25-33.

Gao Y Z, Chen Q, Lin S, et al. 2011. Resource manipulation effects on net primary production, biomass allocation and rain-use efficiency of two semiarid grassland sites in Inner Mongolia, China. Oecologia, pattern of $P$. centrasiaticum, while water added in summer increased the proportion of biomass invested into roots and decreased the biomass invested into leaves.

Although we examined only $P$. centrasiaticum for this experiment, we confirmed the allometric biomass partitioning theory and explained the mechanism of $P$. centrasiaticum distribution. The distribution of $P$. centrasiaticum was proved to rely more on soil water content than on soil nutrient content. For instance, as soil nutrient content is low while available soil water is relatively high in shifting sandy dunes (Zhang et al., 2005), few plants can survive, but $P$. centrasiaticum takes dominance because of its unique characters. Our result is helpful for researching the pattern of plant biomass allocation strategies on a larger scale.

\section{Acknowledgments}

This research was funded by grants from the National Basic Research Program of China (2009CB421303), the National Science \& Technology Pillar Program (2011BAC07B02), and the National Natural Science Foundation of China (40871004). We gratefully acknowledge the anonymous reviewers for their constructive comments.

165(4): 855-864.

Guo J L, Li Q F. 2008. Effects of clonal integration on clonal growth in Pennisetum centrasiaticum. Chinese Journal of Grassland, 30(6): 43-48.

Hermans C, Hammond J P, White P J, et al. 2006. How do plants respond to nutrient shortage by biomass allocation? Trends in Plant Science, 11(12): 610-617.

Huang Y X, Zhao X Y, Zhang H X, et al. 2009a. A comparison of phenotypic plasticity between two species occupying different positions in a successional sequence. Ecological Research, 24(6): 1335-1344.

Huang Y X, Zhao X Y, Zhang H X, et al. 2009b. Allometric effects of Agriophyllum squarrosum in response to soil nutrients, water, and population density in the Horqin Sandy Land of China. Journal of Plant Biology, 52(3): 210-219.

Johnston F, Johnston S. 2004. Impacts of road disturbance on soil properties and on exotic plant occurrence in subalpine areas of the Australian Alps. Arctic, Antarctic, and Alpine Research, 36(2): 201-207.

Kobe R K, Iyer M, Walters M B. 2010. Optimal partitioning theory 
revisited: nonstructural carbohydrates dominate root mass responses to nitrogen. Ecology, 91(1): 166-179.

Li F R, Kang L F, Zhang H, et al. 2005. Changes in intensity of wind erosion at different stages of degradation development in grasslands of Inner Mongolia, China. Journal of Arid Environments, 62(4): $567-585$.

Linkohr B I, Williamson L C, Fitter A H, et al. 2002. Nitrate and phosphate availability and distribution have different effects on root system architecture of Arabidopsis. The Plant Journal, 29(6): $751-760$.

Liu S, Gao Y B, Chen S P, et al. 1999. A preliminary study on the clonal growth and adaptive strategy of Pennisetum centrasiaticum and Leymus secalinus. Journal of Desert Research, 19(Suppl.1): 75-78.

McCarthy M C, Enquist B J. 2007. Consistency between an allometric approach and optimal partitioning theory in global patterns of plant biomass allocation. Functional Ecology, 21(4): 713-720.

McConnaughay K D M, Coleman J S. 1999. Biomass allocation in plants: ontogeny or optimality? A test along three resource gradients. Ecology, 80(8): 2581-2593.

Mony C, Koschnick T J, Haller W T, et al. 2007. Competition between two invasive Hydrocharitaceae (Hydrilla verticillata (L.f.) (Royle) and Egeria densa (Planch)) as influenced by sediment fertility and season. Aquatic Botany, 86(3): 236-242.

Müller I, Schmid B, Weiner J. 2000. The effect of nutrient availability on biomass allocation patterns in 27 species of herbaceous plants. Perspectives in Plant Ecology, Evolution and Systematics, 3(2): $115-127$.

Peichl M, Arain M A. 2007. Allometry and partitioning of above- and belowground tree biomass in an age-sequence of white pine forests. Forest Ecology and Management, 253(1-3): 68-80.

Pino J, Sans F X, Masalles R M. 2002. Size-dependent reproductive pattern and short-term reproductive cost in Rumex obtusifolius L. Acta Oecologica, 23(5): 321-328.

Poorter H, Nagel O. 2000. The role of biomass allocation in the growth response of plants to different levels of light, $\mathrm{CO}_{2}$, nutrients and water: a quantitative review. Australian Journal of Plant Physiology, 27(12): 595-607.

R Development Core Team. 2009. R: A Language and Environment for Statistical Computing. Vienna, Austria: R Foundation for Statistical Computing.

Ren A Z, Gao Y B, Wang J L. 2000. Morphological plasticity of Pennisetum centrasiaticum clones in abandoned farmland in ecotone of farming and animal husbandry. Journal of Desert Research, 20(Suppl.1): 33-37.

Shipley B, Meziane D. 2002. The balanced-growth hypothesis and the allometry of leaf and root biomass allocation. Functional Ecology, 16(3): 326-331.

Solow A R. 2005. Power laws without complexity. Ecology Letters, 8(4): 361-363.

Su Y Z, Zhao H L, Li Y L, et al. 2004. Influencing mechanisms of several shrubs on soil chemical properties in semiarid Horqin Sandy Land, China. Arid Land Research and Management, 18(3): 251-263.

Wang J, Yu D, Wang Q. 2008. Growth, biomass allocation, and autofragmentation responses to root and shoot competition in Myriophyllum spicatum as a function of sediment nutrient supply. Aquatic Botany, 89(4): 357-364.

Warton D I, Wright I J, Falster D S, et al. 2006. Bivariate line-fitting methods for allometry. Biological Reviews, 81(2): 259-291.

Weiner J. 2004. Allocation, plasticity and allometry in plants. Perspectives in Plant Ecology, Evolution and Systematics, 6(4): $207-215$

Wipf S. 2010. Phenology, growth, and fecundity of eight subarctic tundra species in response to snowmelt manipulations. Plant Ecology, 207(1): 53-66

Wright I J, Westoby M, Reich P B. 2002. Convergence towards higher leaf mass per area in dry and nutrient-poor habitats has different consequences for leaf life span. Journal of Ecology, 90(3): 534-543.

Wright I J, Reich P B, Westoby M, et al. 2004. The worldwide leaf economics spectrum. Nature, 428(6985): 821-827.

Yang Y H, Luo Y Q. 2011. Isometric biomass partitioning pattern in forest ecosystems: evidence from temporal observations during stand development. Journal of Ecology, 99(2): 431-437.

Zhang D Y, Jiang X H. 2002. Size-dependent resource allocation and sex allocation in herbaceous perennial plants. Journal of Evolutionary Biology, 15(1): 74-83.

Zhang J X, Zhao H L, Zhang T H, et al. 2005. Community succession along a chronosequence of vegetation restoration on sand dunes in Horqin Sandy Land. Journal of Arid Environments, 62(4): 555-566.

Zhao H L, Zhao X Y, Zhang T H, et al. 2004. Plant Strategies and Vegetation Stability in Desertification Process. Beijing: China Ocean Press.

Zhao H L, Zhou R L, Su Y Z, et al. 2007. Processes and mechanisms of soil desertification in semiarid areas, Northern China. Journal of Soil and Water Conservation, 21(3): 1-5. 